\title{
Öğretim Becerileri, Kişilik Özellikleri, Alan Bilgisi ve Mesleki Gelişim Bağlamında Etkili Öğretmen Özellikleri
}

\section{Effective Teacher Characteristics in Terms of Instructional Skills, Personality Traits, Subject Matter Knowledge and Professional Development}

Yazar Bilgileri
Güneş Korkmaz
Dr., Özel Ege Lisesi,
gunes.korkmaz.gk@gmail.com

\begin{tabular}{l}
\hline Makale Bilgileri \\
\hline Anahtar Kelimeler \\
Etkili Öğretmen Özellikleri \\
Öğretim Becerileri \\
Alan Bilgisi \\
Kişilik Özellikleri \\
Mesleki Gelişim
\end{tabular}

\section{Keywords}

Effective Teacher Characteristics Instructional Skills

Subject Matter Knowledge

Personality Traits

Professional Development

\section{Makale Geçmişi}

Geliş: 17.03.2021

Düzeltme: 29.03.2021

Kabul: 08.04.2021

\section{Güneş Korkmaz}

\begin{abstract}
ÖZ
$\mathrm{Bu}$ araştırmanın amacı öğretmenlerin etkili öğretmen özelliklerinde kendilerini nasıl algıladıklarını görev yapılan okul türü, cinsiyet, kıdem ve branş değişkenlerine göre belirlemektir. Araştırmada nedensel karşılaştırma yöntemi kullanılmıştır. Veri toplama aracı olarak "Etkili Öğretmen Özellikleri Envanteri" kullanılmıştır. Çalışma grubunu devlet ve özel okullarında görev yapan 364 öğretmen oluşturmaktadır. Betimsel istatistikler ile karşılaştırma testleri kullanılmıştır. Araştırmada devlet okulu öğretmenlerinin alan bilgisinde kendilerini özel okul öğretmenlerine göre daha yetkin algıladığı, mesleki gelişimde özel okul öğretmenlerine göre mesleki gelişime daha çok önem verdiğii özel okul ögretmenlerinin ise öğretim becerilerinde kendilerini devlet okulu öğretmenlerine göre daha yetkin algıladıkları görülmüştür. Hem devlet hem de özel okul öğretmenleri kendilerini olumlu kişilik özelliklerinde görmektedir. Cinsiyet ve branş ise alan bilgisi, öğretim becerileri, kişilik özellikleri ve mesleki gelişim özelliklerinde farklılık yaratmamaktadır. Kıdem alan bilgisi, kişilik özellikleri ve mesleki gelişim özelliklerinde farklılık yaratmamakta ancak 0-5 yıl kıdeme sahip öğretmenlerin 21 yıl ve üzeri kıdeme sahip olanlara göre kendilerini öğretim becerilerinde daha yetkin algıladığı sonucuna ulaşılmıştır.
\end{abstract}

\begin{abstract}
This study aims to determine teachers' perceptions of effective teacher characteristics according to school type, gender, seniority, and branch. The study was designed according to causal-comparative research design. "Effective Teacher Characteristics Inventory" was used to collect data. The sample consists of 364 teachers working in public and private schools. Descriptive statistics and comparison tests were used to analyze the data. The results revealed that public school teachers perceive themselves as more competent in terms of subject matter knowledge and give more importance to professional development than private school teachers; private school teachers perceive themselves as more competent than public school teachers in terms of instructional skills. However, in terms of personality traits, both public and private school teachers perceive themselves as positive. Gender and branch do not make any significant difference in subject matter knowledge, instructional skills, personality traits, and professional development. Seniority does not make a significant difference in terms of personality traits and professional development. However, teachers with $0-5$ years of experience perceive themselves as more competent in terms of instructional skills than those with experience of 21 years or more.
\end{abstract}




\section{Giriş}

Günümüz dünyasında yaşanan toplumsal, kültürel, ekonomik ve politik değişim eğitimde de büyük çapta bir dönüşüme neden olmaktadır. Eğitim ile ilgili olarak yaşanan değişimden en fazla etkilenen meslek grubu kuşkusuz ki öğretmenlerdir. 2020 yılında başlayan küresel salgın (COVID-19) döneminde yaşananlardan da anlaşılacağı üzere, toplumların ihtiyaç duyduğu kişiler arasında en ön safta bilim insanları, sağlık profesyonelleri ve öğretmenler yer almıştır. Dolayısıyla, günümüzde öğretmenlerin sahip olması gereken sorumluluklar giderek artmıştır. Dijital alandaki gelişmelerin eğitime yansıması, değişen koşullara uyum sağlama ihtiyacı, bilgi çağı ve 21. yüzyıl becerileri olarak adlandırılan becerilerin öğrencilere kazandırılması gibi gereksinimlerle birlikte, öğretmen yeterlilikleri daha kapsamlı bir hâl almıştır. Bu nedenle, çağımıza uygun etkili öğretmen özelliklerinin yeniden gündeme getirilmesi, bu özelliklerin kuramsal olarak tartışılması ve bu özellikler bağlamında öğretmenlerin kendilerini hangi konumda gördüğünün belirlenmesi eğitimin hem kuramsal hem de uygulama boyutuna katkı sağlayacaktır. Ayrıca, etkili öğretmen özelliklerinin belirlenmesi; öğretmen eğitiminde kullanılan eğitim programlarının güncellenmesi, öğretmen eğitiminde kalitenin arttırılması ve dolayısıyla öğretmenlerin niteliklerinin yeterliliklerinin iyileştirilmesi açısından da oldukça önemlidir.

Öğretmenlerin sahip olması gereken özelliklerin neler olduğunun belirlenmesi oldukça zordur. Bunun nedeni, öğretmenin sahip olması gereken bilgi, beceri, tutum ve davranışların çok geniş bir içeriğe sahip olması, mesleğin tarih boyunca geçirdiği evrim süreci ve öğretmenlik mesleğinden beklenen rol ve sorumlulukların birçok açıdan (toplumsal, kültürel, siyasi vb.) göreceli olmasından kaynaklanmaktadır. Örneğin, alanyazında birçok araştırmacı, öğretmen özelliklerini üç farklı kategoride açıklamıştır: (1) pasif bir teknisyen (passive technician) olarak öğretmen, (2) yansıtıcı bir uygulayıcı olarak öğretmen (reflective practitioner) ve dönüştürücü bir entelektüel olarak öğretmen (transformative intellectual) (Condrat, 2018; Giroux ve McLaren, 1986; Kumaravadivelu, 2003; Morgan, 2009; Saygıll, 2013). Bu bağlamda, pasif bir teknisyen olarak öğretmen uzmanlar tarafından üretilen bilgilerin öğrencilere aktarımından sorumludur; bu bilgileri, geçerliğini sorgulamaksızın ve öğrenci ihtiyaçlarını dikkate almaksızın öğrencilere aktarır (Tezgiden-Cakcak, 2016); yansıtıcı bir uygulayıcı olarak öğretmen ise bilgiyi kendisi üreten, karşılaştığı bilgileri eleştirel bir süzgeçten geçirerek derinlemesine sorgulayan ve öğrencileri tarafından eleştirilmeye açık olan bireyleri ifade etmektedir (Boyd, Boll, Brawner ve Villaume, 1998; Larrivee, 2008; Schön, 1987). Son olarak, dönüştürücü bir entelektüel olarak öğretmen ise, güncel gelişmeleri takip eden, öğrencilerini sorgulama, eleştirel düşünme ve problem çözme konusunda destekleyen, toplumsal değişimi gerçekleştirmeyi hedefleyen sorumlulardır (Kumaravadivelu, 2003). Özetle, pasif öğretmen bilginin aktarılmasında bir "aracı (conduit)", yansıtıcı bir uygulayıcı olarak öğretmen öğrenmeyi kolaylaştırıcı bir rehber (facilitator) ve 
dönüştürücü bir entelektüel olarak öğretmen ise toplumsal dönüşümü hedefleyen değişim elçileridir (change agents) (Kumaravadivelu, 2003).

Öğretmenlerle ilişkilendirilen bu rol ve sorumluluklar incelendiğinde, bu üç kategorinin içerisinde yer alan özelliklerin alanyazında yer alan diğer bir sınıflandırma ile ilişkili olduğu görülmektedir. Etkili öğretmen özellikleri ile ilgili alanyazında, bu özelliklerin “alan bilgisinde yetkinlik", “öğretim becerileri”, “kişilik özellikleri” ve "mesleki gelişim” olarak dört temel boyutta ele alınabileceği görülmektedir (Gholam ve Kobeissi, 2012; Kim, Dar-Nimrod ve MacCann, 2018; Moran, 2005; Polk, 2006; Raufelder vd., 2016; Swainston, 2008; Toraman ve Çakmak, 2020). “Alan bilgisinde yetkinlik" kategorisi ile ilgili öğretmen özellikleri incelendiğinde, bu özelliklerin konu hakimiyeti, pedagoji ve içerik bilgisi ile ilişkilendirildiği; "öğretim becerileri” kategorisi için olumlu bir öğrenme ortamı oluşturabilme, çeşitli öğretim stratejileri, yöntem veya tekniklerini etkili kullanma, konuyu günlük yaşamla ilişkilendirerek sunabilme, derse hazırlıklı gelme; güler yüzlü olma, tutarlı olma, kendine güven, dürüst olma, öğrenci görüşlerini önemseme, etkili iletişim kurma, samimi olma, olumlu bir tutuma sahip olma, empati kurma, öğrencilerine rol model olma ile; "kişilik özellikleri" ile ilgili özellikler esnek, yaratıcı, hoşgörülü olma, demokratik bir tutuma sahip olma, öğrencilerinin duygularını ve ihtiyaçlarını önemseme, öğrencilerinde etki bırakabilme ile ilişkilidir (Toraman, 2019). Son olarak "mesleki gelişim" ile ilgili özellikler ise kişisel gelişime önem verme, hayat boyu öğrenmenin öneminin farkında olma, mesleğiyle ilgili araştırmaları izleme, meslektaşlarıyla işbirliği yapma, kendi eğitimine yatırım yapma, kendi alanıyla ilgili konferans vb. etkinlikler ve hizmet içi eğitimlere katılma gibi özelliklerdir (Toraman ve Çakmak, 2020).

$\mathrm{Bu}$ araştırmada öğretmenlerin etkili öğretmen özellikleri açısından kendilerini nasıl algıladıklarını belirlemek amaçlanmıştır. Bu temel amaç çerçevesinde aşağıdaki sorulara yanıt aranmıştır:

1. Öğretmenlerin etkili öğretmen özelliklerine yönelik algıları görev yaptıkları okul türüne (devlet ve özel okul) göre farklılaşmakta mıdır?

2. Öğretmenlerin etkili öğretmen özelliklerine yönelik algıları cinsiyete göre farklılaşmakta midir?

3. Öğretmenlerin etkili öğretmen özelliklerine yönelik algıları kıdeme göre farklılaşmakta midır?

4. Öğretmenlerin etkili öğretmen özelliklerine yönelik algıları branşlara göre farklılaşmakta midır? 


\section{Yöntem}

Araştırma Çanakkale Onsekiz Mart Üniversitesi Lisansüstü Eğitim Enstitüsü Etik Kurulunun 11.03.2021 tarihli ve 05/34 sayılı izni ile yürütülmüştür.

\section{Araştırmanın Deseni}

Araştırmada nedensel karşılaştırma yöntemi kullanılmıştır. Nedensel karşılaştırma araştırmaları gruplar arasındaki farklılıkların nedenlerini ve sonuçlarını, koşullar ve katılımcılar üzerinde herhangi bir müdahale olmaksızın belirlemeyi amaçlayan araştırmalardır (Büyüköztürk, Kılıç-Çakmak, Akgün, Karadeniz ve Demirel, 2009).

\section{Çalışma Grubu}

Araştırmada evren belirlenmemiştir. Araştırma verileri Türkiye'de görev yapan ve kolay ulaşılabilecek öğretmenlerden elde edilmiştir. Ayrıca katılımda en önemli ölçüt gönüllülük ilkesi olmuştur. Pandemi döneminde olunduğu için yüz yüze uygulamalardan kaçınılmış ve uygulamalar çevrimiçi ortamda Google Forms aracılığıyla gerçekleştirilmiştir. Pandemi şartları ve gönüllülük ilkesi örneklemi amaçlı örneklem hâline getirmiştir. Kolay ulaşılabilir örnekleme yönteminde, araştırmacılar araştırma evrenini oluşturacak özellikleri belirler ve bu özelliklere sahip bireylere ulaşmaya çalışır (Büyüköztürk vd., 2009).

Katılımcılara, envanterdeki maddelerin cevaplanmasından önce, bilgilendirilmiş gönüllü onam formu sunulmuştur. Veriler çevrimiçi ortamda toplandığı için, onam formuna "Araştırmaya katılmaya onam veriyorum" kutucuğu eklenmiştir. Araştırmaya onam vermeyen katılımcılar için envanterde yer alan maddelerin bulunduğu sayfa açılmamıştır. Dolayısıyla, sadece araştırmaya gönüllü katılım için onam veren öğretmenler envanterde yer alan maddelerin bulunduğu sayfaya yönlendirilmiştir. Çalışma grubunu devlet ve özel okullarda görev yapan 364 öğretmen oluşturmuştur. Çalışma grubundaki öğretmenlerin demografik özellikleri Tablo 1'de gösterilmiştir.

Tablo 1. Çalışma Grubundaki Öğretmenlerin Demografik Özellikleri

\begin{tabular}{|c|c|c|c|c|c|}
\hline \multirow{2}{*}{\multicolumn{2}{|c|}{ Değişkenler }} & \multicolumn{2}{|c|}{ Özel Okul } & \multicolumn{2}{|c|}{ Devlet Okulu } \\
\hline & & $f$ & $\%$ & $f$ & $\%$ \\
\hline \multirow{2}{*}{ Cinsiyet } & Erkek & 44 & 27.2 & 60 & 29.7 \\
\hline & Kadın & 118 & 72.8 & 142 & 70.3 \\
\hline \multirow{5}{*}{ Kidem } & 0-5 Yil & 66 & 40.7 & 5 & 2.5 \\
\hline & 6-10 Y1l & 39 & 24.1 & 13 & 6.4 \\
\hline & $11-15 Y_{11}$ & 38 & 23.5 & 52 & 25.7 \\
\hline & $16-20 Y_{11}$ & 13 & 8 & 52 & 25.7 \\
\hline & 21 Yıl ve üzeri & 6 & 3.7 & 80 & 39.6 \\
\hline
\end{tabular}




\begin{tabular}{llllll}
\hline \multirow{6}{*}{ Türkçe } & 41 & 25.3 & 42 & 20.8 \\
Matematik & 33 & 20.4 & 50 & 24.8 \\
Franş Bilimleri & 19 & 11.7 & 34 & 16.8 \\
Sosyal Bilimler & 21 & 13 & 28 & 13.9 \\
& İngilizce & 19 & 11.7 & 17 & 8.4 \\
& Psikolojik Danışmanlık ve Rehberlik & 16 & 9.9 & 13 & 6.4 \\
Müzik & 6 & 3.7 & 8 & 4 \\
Görsel Sanatlar & 3 & 1.9 & 5 & 2.5 \\
Beden Eğitimi & 2 & 1.2 & 3 & 1.5 \\
Teknoloji Tasarım & 2 & 1.2 & 2 & 1 \\
\hline Toplam & 162 & 100 & 202 & 100 \\
\hline
\end{tabular}

\section{Veri Toplama Araçları}

Araştırmada veri toplama aracı olarak Toraman ve Çakmak (2020) tarafından öğretmenlerin etkili öğretim özelliklerine yönelik görüşlerini belirlemek amacıyla geliştirilmiş “Etkili Öğretmen Özellikleri Envanteri" kullanılmıştır.

\section{Etkili Öğretmen Özellikleri Envanteri:}

Etkili Öğretmen Özellikleri Envanteri içerisinde her biri birbirinden bağımsız dört ayrı ölçek bulunmaktadır: (1) Etkili Öğretmen Alan Bilgisi Ölçeği, (2) Etkili Öğretmen Öğretim Becerileri Ölçeği, (3) Etkili Öğretmen Kişilik Özellikleri Ölçeği ve (4) Etkili Öğretmen Mesleki Gelişim Özellikleri Ölçeği. $\mathrm{Bu}$ ölçekler doğrulayıc faktör analizinde birbiri ile kovaryans gösterdiğinden ve bir ölçek yapısını doğrulayamamış olmasından dolayı, ölçekler birbirinden bağımsız kalmıştır. Bu nedenle, veri toplama aracı ölçek değil envanter olarak adlandırılmıştır. Envanterde yer alan Etkili Öğretmen Alan Bilgisi Ölçeği'nden alınabilecek en düşük puan dört, en yüksek puan 20'dir. Etkili Öğretmen Öğretim Becerileri Ölçeği kendi içinde üç alt boyuttan oluşmaktadır. Alt boyutlar birbiriyle ve öğretim becerileriyle ilişkilidir. Bu nedenle hem üç alt puan hem de tek toplam puan olarak değerlendirilebilir. Ölçekten alınabilecek en düşük puan on, en yüksek puan 50'dir. Etkili Öğretmen Kişilik Özellikleri Ölçeği'nden alınabilecek en düşük puan yedi, en yüksek puan 35 ve Etkili Öğretmen Mesleki Gelişim Özellikleri Ölçeği'nden alınabilecek en düşük puan dört, en yüksek puan 20'dir. Sonuç olarak, Etkili Öğretmen Özellikleri Envanteri'nde toplam 25 madde yer almaktadır. Envanterde yer alan tüm ölçekler 5’li Likert biçiminde düzenlenmiştir (Hiçbir zaman [1], Nadiren [2], Bazen [3], Sık sık [4] ve Her zaman [5]).

Envanter içerisinde yer alan her ölçek için güvenirlik değerleri, (1) Etkili Öğretmen Alan Bilgisi Ölçeği için 0,82; (2) Etkili Öğretmen Öğretim Becerileri Ölçeği için 0,74; (3) Etkili Öğretmen Kişilik Özellikleri Ölçeği için 0,86 ve (4) Etkili Öğretmen Mesleki Gelişim Özellikleri Ölçeği için ise 0,77'dir. İlgili literatürde bu değerler yüksek güvenirlik değeri olarak kabul edilmektedir (Büyüköztürk, 2013; Field, 2018; Özdamar, 2013). 


\section{Verilerin Analizi}

Verilerin analizinde betimsel istatistikler ile karşılaştırma testleri kullanılmıştır. Yapılan Kolmogorov-Smirnov normallik testi sonucuna göre, Etkili Öğretmen Alan Bilgisi Ölçeği, Etkili Öğretmen Öğretim Becerileri Ölçeği, Etkili Öğretmen Kişilik Özellikleri Ölçeği ve Etkili Öğretmen Mesleki Gelişim Özellikleri Ölçeği toplam puanlarının normallik dağılım göstermediği ( $\mathrm{p}<.05)$ belirlenmiştir. Bu nedenle karşılaştırma testlerinde Mann-Whitney U Testi ile Kruskal Wallis Testi kullanılmıştır.

\section{Bulgular}

Bu bölümde, özel ve devlet okulundan katılan öğretmenlerin etkili öğretmen envanterinin dört bağımsız ölçeğine verdikleri yanıtlar incelenmiştir. Öğretmenlerin envanter maddelerine verdikleri yanıtlar Tablo 2'de gösterilmiştir.

Tablo 2. Öğretmenlerin Etkili Öğretmenlik Algıları

\begin{tabular}{|c|c|c|c|c|}
\hline \multirow[t]{2}{*}{ Maddeler } & \multicolumn{2}{|c|}{ Özel Okul } & \multicolumn{2}{|c|}{ Devlet Okulu } \\
\hline & $N$ & $X(S s)$ & $N$ & $X(S s)$ \\
\hline \multicolumn{5}{|l|}{ Etkili Öğretmen Alan Bilgisi } \\
\hline Konuyla ilgili bilgileri gerektiğinde detaylandırırım. & 162 & $4.2(0.8)$ & 202 & $3.7(1.2)$ \\
\hline $\begin{array}{l}\text { Öğrencilerin ek bilgi (derinleşme/detaylandırma) gerektiren sorularına yanıt } \\
\text { veririm. }\end{array}$ & 162 & $4.2(0.8)$ & 202 & $3.9(1)$ \\
\hline Öğrencilerimi konuyla ilgili ek bilgi alabilecekleri kaynaklara yönlendiririm. & 162 & $4.3(0.8)$ & 202 & $3.8(1.1)$ \\
\hline Konuyla ilgili örnek çeşitliliğinden yararlanırım. & 162 & $1.06(0.7)$ & 202 & $3.8(1.1)$ \\
\hline \multicolumn{5}{|l|}{ Etkili Öğretmen Öğretim Becerileri } \\
\hline Değerlendirmede çeşitli yöntem ve tekniklerden yararlanırım. & 162 & $4.3(0.8)$ & 202 & $4.1(0.9)$ \\
\hline $\begin{array}{l}\text { Uygun öğrenme stratejilerinden (tekrar, gözden geçirme, kavram haritaları } \\
\text { vb.) yararlanırım. }\end{array}$ & 162 & $4.3(0.9)$ & 202 & $3.9(1)$ \\
\hline $\begin{array}{l}\text { Uygun öğretme stratejilerinden (buluş yoluyla, sunuş yoluyla, araştırma- } \\
\text { inceleme yoluyla) yararlanırım. }\end{array}$ & 162 & $4.3(0.8)$ & 202 & $3.9(1)$ \\
\hline $\begin{array}{l}\text { Öğretim ilkelerini (somuttan soyuta, yaşamla ilişkilendirme, yakından } \\
\text { uzağa, kolaydan zora vb.) uygularım. }\end{array}$ & 162 & $4.3(0.8)$ & 202 & $3.9(1)$ \\
\hline Öğrencilerin bireysel farklılıklarını dikkate alırım. & 162 & $4.3(0.9)$ & 202 & $3.9(1)$ \\
\hline Anlaşılmayan konuların tekrarını yaparım. & 162 & $4.2(0.9)$ & 202 & $3.9(1.1)$ \\
\hline Uygun çeşitlilikte ve sıklıkta pekiştireç kullanırım. & 162 & $4.3(0.8)$ & 202 & $4.0(0.9)$ \\
\hline Öğrencilerimi derse motive ederim. & 162 & $4.2(0.8)$ & 202 & $3.9(1)$ \\
\hline Uygun sınıf yönetimi yaklaşımlarından yararlanırım. & 162 & $4.42(0.7)$ & 202 & $3.9(1)$ \\
\hline Sınıfta demokratik davranış sergilerim. & 162 & $4.3(0.7)$ & 202 & $3.9(1)$ \\
\hline \multicolumn{5}{|l|}{ Etkili Öğretmen Kişilik Özellikleri } \\
\hline Öğrencilerime adil davranırım. & 162 & $4.5(0.5)$ & 202 & $4.5(0.5)$ \\
\hline Öğrencilerime saygı gösteririm. & 162 & $4.5(0.5)$ & 202 & $4.5(0.5)$ \\
\hline Öğrencilerime karşı olumlu yaklaşım sergilerim. & 162 & $4.4(0.4)$ & 202 & $4.5(0.4)$ \\
\hline Öğrencilerime karşı dürüst davranırım. & 162 & $4.5(0.5)$ & 202 & $4.5(0.5)$ \\
\hline Sorumluluklarımı yerine getiririm. & 162 & $4.6(0.4)$ & 202 & $4.5(0.5)$ \\
\hline Eleştiriye açık bir tutum gösteririm. & 162 & $4.4(0.5)$ & 202 & $4.4(0.4)$ \\
\hline Öğrencilerime karşı samimi (içten) davranırım. & 162 & $4.51(0.5)$ & 202 & $4.4(0.5)$ \\
\hline \multicolumn{5}{|l|}{ Etkili Öğretmen Mesleki Gelişim Özellikleri } \\
\hline Mesleki gelişimime önem veririm. & 162 & $4.3(0.8)$ & 202 & $4.2(0.8)$ \\
\hline Yenilikleri izlerim. & 162 & $4.2(0.8)$ & 202 & $4.3(0.8)$ \\
\hline Günceli takip ederim. & 162 & $4.1(0.8)$ & 202 & $4.3(0.7)$ \\
\hline Yaşam boyu öğrenmeyi önemserim. & 162 & $4.2(0.8)$ & 202 & $4.3(0.8)$ \\
\hline
\end{tabular}


Etkili öğretmen özellikleri açısından, özel okul öğretmenlerinin devlet okulu öğretmenlerine göre kendilerini, konuyla ilgili örnek çeşitliliğinden daha az yararlandıkları biçiminde algıladıkları; etkili öğretim becerilerinde özel okul öğretmenlerinin genel olarak kendilerini daha yüksek beceriye sahip olarak algıladıkları belirlenmiştir. Etkili öğretmen kişilik ve mesleki gelişim özelliklerinde devlet ve özel okul öğretmen algılarının yüksek düzeyde olduğu saptanmıştır. Okul türüne göre öğretmenlerin etkili öğretmen özellikleri karşılaştırılmıştır. Sonuçlar Tablo 3'te özetlenmiştir.

Tablo 3. Devlet ve Özel Okul Öğretmenlerinin Etkili Öğretmen Özelliklerinin Karşılaştırılması (MannWhitney U Testi)

\begin{tabular}{lllllll}
\hline Ölçek & Okul Türü & $N$ & $X$ & $S s$ & $U$ & \multirow{2}{*}{$\boldsymbol{P}$} \\
\hline \multirow{2}{*}{ Alan Bilgisi Yeterliliği } & Özel Okul & 161 & 13.8 & 1.6 & \multirow{2}{*}{8820.5} & \multirow{2}{*}{0.000} \\
& Devlet Okulu & 202 & 15.3 & 2.2 & & \\
\hline \multirow{2}{*}{ Öğretim Becerileri } & Özel Okul & 161 & 42.9 & 2.8 & \multirow{2}{*}{11227.5} & \multirow{2}{*}{0.000} \\
& Devlet Okulu & 202 & 39.8 & 5.8 & & \\
\hline \multirow{2}{*}{ Kişilik Özellikleri } & Özel Okul & 161 & 31.5 & 1.4 & \multirow{2}{*}{16263.5} & \multirow{2}{*}{0.919} \\
& Devlet Okulu & 202 & 31.4 & 1.3 & & \\
\hline \multirow{2}{*}{ Mesleki Gelişim } & Özel Okul & 161 & 16.8 & 1.6 & \multirow{2}{*}{14371.5} & \multirow{2}{*}{0.043} \\
\cline { 2 - 5 } & Devlet Okulu & 202 & 17.1 & 1.7 & & \\
\hline
\end{tabular}

Devlet okulu öğretmenleri anlamlı biçimde kendilerini özel okul öğretmenlerinde alan bilgisine daha hâkim olarak algılamaktadır $(\mathrm{U}=8820.5, \mathrm{p}<.05)$. Özel okul öğretmenleri anlamlı biçimde kendilerini devlet okulu öğretmenlerinden öğretim becerilerinde daha hâkim olarak algılamaktadır (U=11227.5, p<.05). Kişilik özelliklerinde devlet ve özel okul öğretmenlerinin alg1sında bir farklılık bulunmamaktadır (U=16263.5, p>.05). Devlet okulu öğretmenlerinin anlamlı biçimde kendilerini özel okul öğretmenlerinden mesleki gelişimde daha gelişime açık olarak algılamaktadır (U=14371.5, p<.05). Cinsiyete göre öğretmenlerin etkili öğretmen özellikleri karşılaştırılmıştır. Sonuçlar Tablo 4'te özetlenmiştir.

Tablo 4. Kadın ve Erkek Öğretmenlerin Etkili Öğretmen Özelliklerinin Karşılaştırılması (MannWhitney U Test)

\begin{tabular}{lllllll}
\hline Ölçek & Cinsiyet & $N$ & $X$ & $S s$ & $U$ & \multirow{2}{*}{$\boldsymbol{~}$} \\
\hline \multirow{2}{*}{ Alan Bilgisi Yeterliliği } & Erkek & 104 & 14.7 & 2.2 & \multirow{2}{*}{13098} & \multirow{2}{*}{0.638} \\
& Kadın & 260 & 14.6 & 4.9 & & \\
\hline \multirow{2}{*}{ Öğretim Becerileri } & Erkek & 104 & 40.6 & 4.9 & \multirow{2}{*}{12189} & \multirow{2}{*}{0.141} \\
& Kadın & 260 & 41.3 & 5 & & \\
\hline \multirow{2}{*}{ Kişilik Özellikleri } & Erkek & 104 & 31.4 & 1.4 & \multirow{2}{*}{12866} & \multirow{2}{*}{0.460} \\
& Kadın & 260 & 31.6 & 1.4 & & \\
\hline \multirow{2}{*}{ Mesleki Gelişim } & Erkek & 104 & 16.8 & 1.7 & \multirow{2}{*}{12621.5} & \multirow{2}{*}{0.314} \\
\hline
\end{tabular}

Erkek ve kadın öğretmenlerin alan bilgisi algısında anlamlı bir farklılık bulunmamaktadır $(\mathrm{U}=13098, \mathrm{p}>.05)$. Benzer şekilde, erkek ve kadın öğretmenlerin öğretim becerileri algısında anlamlı farklılık bulunmamaktadır (U=12189, p>.05). Erkek ve kadın öğretmenlerin kişilik özellikleri algısında anlamlı farklılık bulunmamaktadır ( $\mathrm{U}=12866$, p>.05). Erkek ve kadın öğretmenlerin mesleki gelişime 
yönelik algılarında anlamlı bir farklılık bulunmamaktadır ( $U=12621.5, p>.05)$. Öğretmenlerin etkili öğretmenlik özellikleri kıdeme göre karşılaştırılmış ve karşılaştırma sonuçları Tablo 5'te gösterilmiştir.

Tablo 5. Farklı Kıdeme Sahip Öğretmenlerin Etkili Öğretmen Özelliklerinin Karşılaştırılması (Kruskal Wallis Test)

\begin{tabular}{|c|c|c|c|c|c|c|c|c|}
\hline Ölçek & Kidem & $N$ & $X$ & Ss & $X^{2}$ & $s d$ & $p$ & Anlamlı Fark \\
\hline \multirow{5}{*}{$\begin{array}{l}\text { Alan Bilgisi } \\
\text { Yeterliliği }\end{array}$} & $0-5 Y_{11}$ & 71 & 14.3 & 1.6 & \multirow{5}{*}{7.7} & \multirow{5}{*}{4} & \multirow{5}{*}{0.103} & \multirow{5}{*}{-------- } \\
\hline & $6-10 Y_{11}$ & 52 & 14.3 & 1.9 & & & & \\
\hline & $11-15 Y_{11}$ & 90 & 14.8 & 2.1 & & & & \\
\hline & $16-20 Y_{11}$ & 65 & 14.9 & 2.2 & & & & \\
\hline & $21 Y_{1}$ l ve üzeri & 86 & 14.8 & 2.6 & & & & \\
\hline \multirow{5}{*}{$\begin{array}{l}\text { Öğretim } \\
\text { Becerileri }\end{array}$} & $0-5 Y_{11}$ & 71 & 42.8 & 3.4 & \multirow{5}{*}{17.6} & \multirow{5}{*}{4} & \multirow{5}{*}{0.001} & \multirow{5}{*}{$0-5 Y_{11}>21 Y_{1} l$ ve Üzeri } \\
\hline & 6-10 Y 11 & 52 & 42.1 & 4.1 & & & & \\
\hline & 11-15 Yil & 90 & 40.8 & 4.9 & & & & \\
\hline & $16-20 Y_{11}$ & 65 & 41.2 & 5.1 & & & & \\
\hline & $21 Y_{1}$ l ve üzeri & 86 & 39.5 & 5.9 & & & & \\
\hline \multirow{5}{*}{$\begin{array}{l}\text { Kişilik } \\
\text { Özellikleri }\end{array}$} & $0-5 Y_{11}$ & 71 & 31.3 & 1.2 & \multirow{5}{*}{4.6} & \multirow{5}{*}{4} & \multirow{5}{*}{0.332} & \\
\hline & 6-10 $Y_{11}$ & 52 & 31.8 & 1.4 & & & & \\
\hline & $11-15 Y_{11}$ & 90 & 31.6 & 1.5 & & & & --------- \\
\hline & $16-20 Y_{11}$ & 65 & 31.5 & 1.1 & & & & \\
\hline & $21 Y_{1} l$ ve üzeri & 86 & 31.5 & 1.4 & & & & \\
\hline \multirow{5}{*}{$\begin{array}{l}\text { Mesleki } \\
\text { Gelişim }\end{array}$} & $0-5 Y_{11}$ & 71 & 16.8 & 1.8 & \multirow{5}{*}{4.9} & \multirow{5}{*}{4} & \multirow{5}{*}{0.298} & \multirow{5}{*}{--------- } \\
\hline & 6-10 Y1l & 52 & 16.9 & 1.5 & & & & \\
\hline & $11-15 Y_{11}$ & 90 & 16.9 & 1.7 & & & & \\
\hline & $16-20 Y_{11}$ & 65 & 17.4 & 1.5 & & & & \\
\hline & 21 Yıl ve üzeri & 86 & 16.9 & 1.7 & & & & \\
\hline
\end{tabular}

Farklı kıdeme sahip öğretmenlerin alan bilgisi algısında anlamlı farklılık bulunmamaktadır $\left(X^{2}(4)=7.7, p>.05\right)$. Ancak farklı kıdeme sahip öğretmenlerin öğretim becerileri algısında anlamlı farklılık saptanmıştır $\left(\mathrm{X}^{2}(4)=17.6, \mathrm{p}<.05\right)$. Parametrik olmayan Dunn-Bonferroni çoklu karşılaştırma testine göre, kıdemi 0-5 yıl arası olanların öğretim becerisi algıları 21 yıl ve üzerinde olan öğretmenlerden daha yüksektir. Farklı kıdeme sahip öğretmenlerin kişilik özellikleri algısında anlamlı bir farklılık bulunmamaktadır $\left(X^{2}(4)=4.6, p>.05\right)$. Benzer şekilde, farklı kıdeme sahip öğretmenlerin mesleki gelişime yönelik algılarında anlamlı bir farklılık bulunmamaktadır $\left(X^{2}(4)=4.9, p>.05\right)$. Branşa göre öğretmenlerin etkili öğretmen özellikleri karşılaştırılmıştır. Sonuçlar Tablo 6’da özetlenmiştir.

Tablo 6. Farklı Branştaki Öğretmenlerin Etkili Öğretmen Özelliklerinin Karşılaştırılması (Kruskal Wallis Test)

\begin{tabular}{|c|c|c|c|c|c|c|c|}
\hline Ölçek & Branş & $N$ & $X$ & Ss & $X^{2}$ & $s d$ & $p$ \\
\hline \multirow{10}{*}{$\begin{array}{l}\text { Alan Bilgisi } \\
\text { Yeterliliği }\end{array}$} & Türkçe & 83 & 14.8 & 2 & \multirow{10}{*}{4.3} & \multirow{10}{*}{9} & \multirow{10}{*}{0.893} \\
\hline & Matematik & 83 & 14.7 & 2.2 & & & \\
\hline & Fen Bilimleri & 53 & 14.8 & 2.5 & & & \\
\hline & Sosyal Bilimler & 49 & 14.6 & 2.4 & & & \\
\hline & İngilizce & 36 & 14.6 & 1.8 & & & \\
\hline & Psikolojik Danışmanlık ve Rehberlik & 29 & 14.3 & 1.9 & & & \\
\hline & Müzik & 14 & 14.4 & 2.3 & & & \\
\hline & Görsel Sanatlar & 8 & 13.9 & 1.5 & & & \\
\hline & Beden Eğitimi & 5 & 13.8 & 2.3 & & & \\
\hline & Teknoloji Tasarım & 4 & 14.8 & 0.9 & & & \\
\hline
\end{tabular}




\begin{tabular}{|c|c|c|c|c|c|c|c|}
\hline \multirow{10}{*}{$\begin{array}{l}\text { Öğretim } \\
\text { Becerileri }\end{array}$} & Türkçe & 83 & 42.1 & 4.5 & \multirow{10}{*}{15.5} & \multirow{10}{*}{9} & \multirow{10}{*}{0.078} \\
\hline & Matematik & 83 & 40.1 & 5.1 & & & \\
\hline & Fen Bilimleri & 53 & 40.5 & 4.8 & & & \\
\hline & Sosyal Bilimler & 49 & 40.9 & 6.4 & & & \\
\hline & İngilizce & 36 & 41.3 & 5.1 & & & \\
\hline & Psikolojik Danışmanlık ve Rehberlik & 29 & 41.8 & 3.5 & & & \\
\hline & Müzik & 14 & 42.6 & 3.5 & & & \\
\hline & Görsel Sanatlar & 8 & 41.1 & 4 & & & \\
\hline & Beden Eğitimi & 5 & 43.6 & 4.8 & & & \\
\hline & Teknoloji Tasarım & 4 & 38.5 & 3.1 & & & \\
\hline \multirow{10}{*}{$\begin{array}{l}\text { Kişilik } \\
\text { Özellikleri }\end{array}$} & Türkçe & 83 & 31.4 & 1.4 & \multirow{10}{*}{10.5} & \multirow{10}{*}{9} & \multirow{10}{*}{0.315} \\
\hline & Matematik & 83 & 31.6 & 1.5 & & & \\
\hline & Fen Bilimleri & 53 & 31.5 & 1.1 & & & \\
\hline & Sosyal Bilimler & 49 & 31.7 & 1.2 & & & \\
\hline & İngilizce & 36 & 31.2 & 1.1 & & & \\
\hline & Psikolojik Danışmanlık ve Rehberlik & 29 & 31.5 & 1.3 & & & \\
\hline & Müzik & 14 & 32.2 & 1.5 & & & \\
\hline & Görsel Sanatlar & 8 & 32.5 & 1.5 & & & \\
\hline & Beden Eğitimi & 5 & 31.4 & 1.5 & & & \\
\hline & Teknoloji Tasarım & 4 & 31.8 & 0.9 & & & \\
\hline \multirow{10}{*}{$\begin{array}{l}\text { Mesleki } \\
\text { Gelişim }\end{array}$} & Türkçe & 83 & 16.8 & 1.4 & \multirow{10}{*}{6.3} & \multirow{10}{*}{9} & \multirow{10}{*}{0.711} \\
\hline & Matematik & 83 & 17.1 & 1.8 & & & \\
\hline & Fen Bilimleri & 53 & 17.1 & 1.7 & & & \\
\hline & Sosyal Bilimler & 49 & 16.7 & 1.9 & & & \\
\hline & İngilizce & 36 & 16.6 & 1.7 & & & \\
\hline & Psikolojik Danışmanlık ve Rehberlik & 29 & 17.3 & 1.5 & & & \\
\hline & Müzik & 14 & 17 & 1.5 & & & \\
\hline & Görsel Sanatlar & 8 & 16.6 & 1.3 & & & \\
\hline & Beden Eğitimi & 5 & 16.8 & 0.8 & & & \\
\hline & Teknoloji Tasarım & 4 & 17.5 & 1.7 & & & \\
\hline
\end{tabular}

Farklı branştaki öğretmenlerin alan bilgisi algısında anlamlı bir farklılık bulunmamaktadır $\left(X^{2}(9)=4.3, p>.05\right)$. Benzer şekilde, farklı branştaki öğretmenlerin öğretim becerileri algısında anlamlı farklılık bulunmamaktadır $\left(\mathrm{X}^{2}(9)=15.5, \mathrm{p}>.05\right)$. Ayrıca, farklı branşlara göre öğretmenlerin kişilik özellikleri algısında anlamlı farklılık bulunmamaktadır $\left(X^{2}(9)=10.5\right.$, p $\left.>05\right)$. Benzer olarak, farklı branştaki öğretmenlerin mesleki gelişimde algılarında anlamlı farklılık bulunmamaktadır $\left(X^{2}(9)=6.3\right.$, $\mathrm{p}>$.05).

\section{Tartışma}

Bu araştırma, öğretmenlerin etkili öğretmen özelliklerinde kendilerini nasıl algıladıklarını görev yapılan okul türü, cinsiyet, kıdem ve branş değişkenlerine göre belirlemek amacıyla gerçekleştirilmiştir.

Özel ve devlet okulundan katılan öğretmenlerin etkili öğretmen envanterinin dört bağımsız ölçeğine verdikleri yantlar incelendiğinde, devlet okulu öğretmenlerinin kendilerini özel okul öğretmenlerine göre alan bilgisinde daha hâkim olarak algılamaktadır. Bu durum, devlet okullarında görev yapan öğretmenlerin genellikle daha fazla kıdeme sahip olmasından kaynaklanabilir. Bununla beraber, özel okul öğretmenlerinin öğretim becerileri bağlamında genel olarak kendilerini daha 
yüksek beceriye sahip olarak algıladıkları belirlenmiştir. Araştırmanın bu bulgusu Eason, Giannangelo ve Franceschini (2009) tarafından gerçekleştirilen çalışmanın bulgularıyla benzerlik göstermektedir. Bu araştırmada da öğrencileri öğrenmeye yönelik motive etme ve uygun öğretme stratejilerinden yararlanma gibi özellikler açısından, özel okul öğretmenlerinin kendilerini devlet okulu öğretmenlerinden daha etkin gördükleri bulgusuna ulaşılmıştır. Bu durum, özel okulda görev yapan öğretmenlerin, öğretim süreci ve öğretim becerileri ile ilgili olarak, okul yönetimi ve veli tarafından sürekli bir gözlem ve değerlendirmeye tabi tutulması ve bu nedenle de öğretim becerilerini geliştirmeye yönelik daha fazla çaba harcadığı şeklinde yorumlanabilir. Diğer bir deyişle, özel okul öğretmenleri, çeşitli değişkenler nedeniyle, öğretim becerilerinde kendilerini devlet okul öğretmenlerinden daha fazla geliştirmek zorunda hissediyor olabilir. Arum (1996) da özel okul öğretmenlerinin öğretim becerilerinde kendini daha fazla geliştirmek zorunda kalmasının nedenini, özel okulların diğer özel okullarla rekabet içerisinde olmasına bağlamıştır. Bununla birlikte, etkili öğretmen kişilik ve mesleki gelişim özelliklerinde devlet ve özel okul öğretmen algılarının yüksek düzeyde olduğu saptanmıştır. Bu durum hem devlet okulu hem de özel okul öğretmenlerinin kişilik özellikleri ve mesleki gelişim özellikleri açısından kendilerini yeterli bulduğu şeklinde yorumlanabilir.

Öğretmenlerin etkili öğretmen özellikleri envanterine verdikleri yanıtlar cinsiyet değişkenine göre incelendiğinde, öğretmenlerin alan bilgisi, öğretim becerileri, kişilik özellikleri ve mesleki gelişime yönelik algısında cinsiyet değişkeninin anlamlı bir farklılık yaratmadığı görülmüştür. Bu bulgu, Öznacar, Güven ve Yılmaz (2017), Tosuntaş, Çubukçu ve Beauchamp (2021), Tran ve Do (2020) tarafından yapılmış çalışmaların bulgularıyla aynı doğrultudadır. Ancak, Antecol, Eren ve Özbeklik (2015), Sansone (2017) ile Minor, Onwuegbuzie, Witcher ve James (2002) tarafından yapılan çalışmalarda, öğretmenlerin etkili öğretmen özelliklerine yönelik algılarının cinsiyete göre değiştiği bulgusuna ulaşılmışır. Bu çalışmalarda, kadın öğretmenlerin etkili öğretmen kişilik özellikleri bağlamında erkek öğretmenlerden kendilerini daha fazla yetkin gördükleri belirtilmiştir.

Kıdeme göre öğretmenlerin etkili öğretmen özellikleri karşılaştırıldığında, farklı kıdeme sahip öğretmenlerin alan bilgisi, kişilik özellikleri ve mesleki gelişime yönelik algısında anlamlı farklılık bulunmamaktadır. Ancak farklı kıdeme sahip öğretmenlerin öğretim becerileri algısında anlamlı farklılık saptanmıştır. Buna göre, kıdemi 0-5 yıl arası olanların öğretim becerisi algıları 21 yıl ve üzerinde olan öğretmenlerden daha yüksektir. Bu durum, 0-5 yıllık bir öğretmenlik tecrübesine sahip öğretmenlerin kıdemli öğretmenlerden daha yetkin hissetmekte olduğunu göstermektedir. Bunun nedeni, yeni mezun öğretmenlerin öğretim ile ilgili bilgi ve becerilere daha fazla odaklanması ve bu konuda kendilerini daha fazla geliştirmiş olmasından kaynaklanabilir. Bu bulgu, Tosuntaş vd. (2021) ve Tran ve Do (2020) tarafından yapılan çalışmaların bulgularıyla benzer özellik göstermektedir. Buna göre, öğretmenlerin meslekteki deneyim süresi arttıkça öğretim becerileri ile ilgili yetkinlik algılarının 
azaldığı sonucuna ulaşılmıştır. Bununla birlikte, araştırmanın bu bulgusu Danişman ve Tanışlı (2018), Minor vd. (2002) ve Sansone (2017) tarafından yapılan çalışmanın bulgularıyla farklılık göstermektedir. Araştırmacılar, öğretmenlerin deneyim süresi arttıkça, öğretim süreçlerinde kendilerini daha yetkin hissettiklerini belirtmektedir.

Öğretmenlerin etkili öğretmen özellikleri envanterine verdikleri yanıtlar branş değişkenine göre incelendiğinde, farklı branştaki öğretmenlerin alan bilgisi, öğretim becerileri, kişilik özellikleri ve mesleki gelişime yönelik algılarında anlamlı bir farklılık bulunmadığı sonucuna ulaşılmıştır. Diğer bir deyişle, etkili öğretmenlik özelliklerinde branş yordayıcı bir değişken değildir. Bu bulgu, Tajeddin ve Alemi (2019) tarafından gerçekleştirilen çalışmanın bulguları ile benzerlik gösterirken, Çalışkan, Güney, Sakhieva, Vasbieva ve Zaitseva (2019) ve Şimşek ve Sarsar (2019) tarafından gerçekleştiren çalışmanın öğretim becerilerine yönelik bulguları ile farklılık göstermektedir.

\section{Sonuç ve Öneriler}

Öğretmenlerin etkili öğretmen özelliklerinde kendilerini nasıl algıladıklarını görev yapılan okul türü, cinsiyet, kıdem ve branş değişkenlerine göre belirlemek amacıyla gerçekleştirilen bu araştırma sonucunda, devlet okulu öğretmenlerinin alan bilgisinde kendilerini özel okul öğretmenlerine göre daha yetkin algıladığı, mesleki gelişimde özel okul öğretmenlerine göre mesleki gelişime daha çok önem verdiği; özel okul öğretmenlerinin ise öğretim becerilerinde kendilerini devlet okulu öğretmenlerine göre daha yetkin algıladıkları görülmüştür. Bununla birlikte, kişilik özellikleri açısından hem devlet hem de özel okul öğretmenleri kendilerini olumlu kişilik özelliklerinde görmektedir. Cinsiyet ve branş değişkenleri ise alan bilgisi, öğretim becerileri, kişilik özellikleri ve mesleki gelişim özelliklerinde farklılık yaratmamaktadır. Benzer şekilde, kıdem alan bilgisi, kişilik özellikleri ve mesleki gelişim özelliklerinde farklılık yaratmamaktadır. Ancak 0-5 yıl kıdeme sahip öğretmenlerin 21 yıl ve üzeri kıdeme sahip olanlara göre kendilerini öğretim becerilerinde daha yetkin algıladığı sonucuna ulaşılmıştır.

Ĕ̆itim Politikasını Belirleyen Kurum ve Kişilere/Karar Vericilere Yönelik Öneriler:

1. Eğitim fakültelerinde öğrenim gören adayların etkili öğretmen özellikleri hakkındaki farkındalıklarının arttırılması için öğretmen yetiştirme eğitim programlarının yeniden gözden geçirilebilir ve bu konuda değerlendirme çalışmaları yapılabilir.

2. Hem devlet hem de özel okullarda görev yapan öğretmenlerin etkili öğretmen özellikleri konusundaki bilgi, beceri ve yetkinliklerini artırmak ve yaşam boyu öğrenmelerine destek olmak için, bu konuda hizmet içi eğitimler düzenlenebilir.

3. Milli Eğitim Bakanlığı tarafından, ulusal çapta yürütülmek üzere, öğretmenlerin etkili öğretmen özellikleri açısından kendilerini değerlendirebildikleri çalışmalar 
gerçekleştirilebilir ve bu çalışma sonuçları tüm öğretmenlerle paylaşılarak öğretmenlerin bu konuda bilgi sahip olması sağlanabilir.

Araştırmacılara Yönelik Öneriler:

1. Etkili öğretmen özelliklerini belirlemeye yönelik, devlet okulu ve özel okullarda öğrenim gören öğrencilerin görüşlerini de inceleyen araştırmalar yapılabilir.

2. Eğitim fakültesinde öğrenim gören öğretmen adaylarının etkili bir öğretmenin sahip olması gereken özellikleri konusunda ne düşündükleri ve kendilerini bu konuda nerede gördüklerine yönelik araştırmalar yapılabilir.

3. Etkili öğretmen özellikleri konusunda öğretmenlerin kendilerini eksik hissettikleri özelliklerin belirlenmesi ile ilgili bir ihtiyaç analizi çalışması yapılabilir.

Uygulayıcılara/Öğretmenlere Yönelik Öneriler:

1. Öğretmenler, yaşam boyu öğrenme ve etkili öğretmen özelliklerini geliştirme amacıyla, ilgili bilimsel araştırmaları takip edip, bu çalışmaların sonuçlarını mesleki uygulamalarına yansıtmaya odaklanarak hem kişisel hem de mesleki gelişimlerine katkı sağlayabilir.

2. Öğretmenler, ders verdikleri sınıf bazında, belirli aralıklarla düzenleyeceği değerlendirme çalışmaları (öğrencilerin öğretmenini değerlendirmesine fırsat vererek) yürütebilir. Bu tür çalışmalar, öğretmenlerin öz değerlendirme yapmasına yardımcı olabilir.

\section{Kaynaklar}

Antecol, H., Eren, O., \& Özbeklik, S. (2015). The effect of teacher gender on student achievement in primary school. Journal of Labor Economics, 33(1), 63-89. http://www.jstor.org/stable/10.1086/677391?origin=ISTOR-pdf sayfasından erişilmiştir.

Arum, R. (1996). Do private schools force public schools to compete? American Sociological Review, 61(1), 29-46. http://www.jstor.org/stable/2096405 sayfasından erişilmiştir.

Boyd, P. C., Boll, M., Brawner, L., \& Villaume, S. K. (1998). Becoming reflective professionals: An exploration of preservice teacher's struggles as they translate language and literacy theory into $\begin{array}{lllll}\text { practice. Action } & \text { 6n }\end{array}$ https://doi.org/10.1080/01626620.1998.10462892

Büyüköztürk, Ş. (2013). Sosyal bilimler için veri analizi el kitabı. Ankara: Pegem.

Büyüköztürk, Ş., Kılıç-Çakmak, E., Akgün, Ö. E., Karadeniz, Ş., \& Demirel, F. (2009). Bilimsel araştırma yöntemleri. Ankara: Pegem.

Condrat, V. (2018). Backward design: when a good ending makes a good beginning. Inspiring Professional Excellence in Teaching Languages (March 16th-17th, 2018) içinde, 64-75. 
Çalışkan, S., Güney, Z., Sakhieva, R., Vasbieva, D., \& Zaitseva, N. (2019). Teachers' views on the availability of web 2.0 tools in education. International Journal of Emerging Technologies in Learning (IJET), 14(22), 70-81. https://doi.org/10.3991/ijet.v14i22.11752

Danişman, Ş., \& Tanışlı, D. (2018). Examination of mathematics teachers' pedagogical content knowledge of probability. MOJES: Malaysian Online Journal of Educational Sciences, 5(2), 16-34. https://mojes.um.edu.my/article/view/12622/8117 sayfasından erişilmiştir.

Eason, R., Giannangelo, D. M., \& Franceschini, L. A. (2009). A look at creativity in public and private schools. Thinking Skills and Creativity, 4(2), 130-137. https://doi.org/10.1016/j.tsc.2009.04.001

Field, A. (2018). Discovering statistics using IBM SPSS Statistics. The USA: Sage.

Gholam, A. P., \& Kobeissi, A. H. (2012). Teacher evaluation instruments/systems in Lebanon and other major Arab countries in comparison to evidenced-based characteristics of effective teacher evaluation instruments (Doctoral Dissertation). ProQuest Dissertations and Theses database. (UMI No. 3544957).

Giroux, H., \& McLaren, P. (1986). Teacher education and the politics of engagement: The case for democratic schooling. Harvard Educational Review, 56(3), 213-239.

Kim, L. E., Dar-Nimrod, I., \& MacCann, C. (2018). Teacher personality and teacher effectiveness in secondary school: Personality predicts teacher support and student self-efficacy but not academic achievement. Journal of Educational Psychology, 110(3), 309-323.

Kumaravadivelu, B. (2003). Beyond methods: Macrostrategies for language teaching. Yale University Press.

Larrivee, B. (2008). Meeting the challenge of preparing reflective practitioners. The New Educator, 4(2), 87-106. https://doi.org/10.1080/15476880802014132

Minor, L. C., Onwuegbuzie, A. J., Witcher, A. E., \& James, T. L. (2002). Preservice teachers' educational beliefs and their perceptions of characteristics of effective teachers. The Journal of Educational Research, 96(2), 116-127. http://dx.doi.org/10.1080/00220670209598798

Moran, C. (2005). Teacher and principal perceptions of dispositional characteristics needed by middle school teachers to be most effective in the classroom (Doctoral Dissertation). ProQuest Dissertations and Theses database. (UMI No. 3199445).

Morgan, B. (2009). Fostering transformative practitioners for critical EAP: Possibilities and challenges. Journal of English for Academic Purposes, 8(2), 86-99. https://doi:10.1016/j.jeap.2008.09.001

Özdamar, K. (2013). Paket programlar ile istatistiksel veri analizi. Eskişehir: Nisan Yayıncılık.

Öznacar, B., Güven, Z., \& Yilmaz, E. (2017). A study into teaching styles of elementary school teachers in terms of several variables. International Journal of Economic Perspectives, 11(1), 552-560. 
Polk, J. A. (2006). Traits of effective teachers. Arts Education Policy Review, 107(4), $23-29$. https://doi.org/10.3200/AEPR.107.4.23-29

Raufelder, D., Nitsche, L., Breitmeyer, S., Keßler, S., Herrmann, E., \& Regner, N. (2016). Students' perception of "good" and "bad" teachers: Results of a qualitative thematic analysis with German adolescents. International Journal of Educational Research, 75, 31-44. https://doi.org/10.1016/j.ijer.2015.11.004

Sansone, D. (2017). Why does teacher gender matter? Economics of Education Review, 61, 9-18.

Saygılı, S. (2013). Sanayi toplumundan bilgi toplumuna geçiş sürecinde eğitimde dönüştürücü bir entelektüel olarak öğretmenler. Uşak Üniversitesi Sosyal Bilimler Dergisi [Özel Sayı], 263-274. http://dx.doi.org/10.1016/j.econedurev.2017.09.004

Schön, D. A. (1987). Educating the reflective practitioner. San Francisco: Jossey-Bass.

Swainston, T. (2008). A reflective resource for performance management, effective teachers in secondary schools. London: Network Continuum.

Şimsek, Ö., \& Sarsar, F. (2019). Investigation of the self-efficacy of the teachers in technological pedagogical content knowledge and their use of information and communication technologies. World Journal of Education, 9(1), 196-208. https://doi.org/10.5430/wje.v9n1p196

Tajeddin, Z., \& Alemi, M. (2019). Effective language teachers as persons: exploring pre-service and inservice teachers' beliefs. The Electronic Journal for English as a Second Language, 22(4). https://eric.ed.gov/?id=EJ1204608 sayfasından erişilmiştir.

Tezgiden-Cakcak, Y. (2016). Öğretmen eğitiminin temel sorunsalı: Nasıl bir öğretmen yetiştirmeyi hedefliyoruz? Eleştirel Pedagoji, 45, 60-68.

Toraman, Ç. (2019). Ortaokul öğretmenlerinin etkili öğretmen özellikleri ile öğretmenlik mesleğini seçme nedenleri üzerine bir araştırma. (Doktora tezi). https://tez.yok.gov.tr sayfasından erişilmiştir.

Toraman, Ç., \& Çakmak, M. (2020). The relationship between effective teacher characteristics and reasons for choosing teaching profession: Development of an effective teacher inventory. International Journal of Assessment Tools in Education, 7(3), 420-435. https://doi.org/10.21449/ijate.707272

Tosuntaş, P. Ş. B., Çubukçu, Z., \& Beauchamp, G. (2021). Teacher performance in terms of technopedagogical content knowledge competencies. Kastamonu Education Journal, 29(1), 63-83. https://doi.org/10.24106/kefdergi.726886

Tran, T. T. T., \& Do, T. X. (2020). Student evaluation of teaching: do teacher age, seniority, gender, and qualification matter? Educational Studies, 1-28. https://doi.org/10.1080/03055698.2020.1771545 


\section{Extended Summary}

Teaching is a profession that requires gaining up-to-date knowledge, skills, and competencies, take an active role in raising individuals who will shape the future of societies for social transformation. The development of societies is closely related to the quality and competencies that the teachers have. Today, the number of responsibilities that teachers should have has increased. When the reflection of the developments in the digital era on education, the need to adapt to changing conditions, the information age, and the needs such as providing students with skills called 21stcentury skills are taken into consideration, teacher competencies have become more extensive. Therefore, the investigation into effective teacher characteristics which are appropriate for our age, analyzing these characteristics will contribute to both the theoretical and practical dimensions of education. In addition, this will provide evidence to update the characteristics of effective teachers, redesign the teacher education curricula, and increase the quality of teacher education. This study aims to determine teachers' perceptions of effective teacher characteristics according to the variables of school type, gender, seniority, and branch.

The study was designed according to causal-comparative research design. Causalcomparative studies aim to determine the causes and consequences of differences between groups without any intervention on the conditions and participants (Büyüköztürk, Kılıç-Çakmak, Akgün, Karadeniz \& Demirel, 2009). The sample of the study consists of 364 teachers working in public and private high schools. The participation in the study was based on volunteering. Face-to-face applications were avoided because of the pandemic, and applications were carried out online via Google Forms. To collect data, the "Effective Teacher Characteristics Inventory" developed by Toraman and Çakmak (2020) was used. In this inventory, there are four separate scales, independent of each other: (1) Subject Matter Knowledge, (2) Instructional Skills, (3) Personality Traits, and (4) Professional Development Traits. Since these scales show covariance with each other in the confirmatory factor analysis and could not verify a scale structure, the scales remained independent of each other. Therefore, the data collection tool is called inventory rather than a scale. The lowest score that can be obtained from the Subject Matter Knowledge Scale is four, and the highest score is 20 . Instructional Skills Scale consists of three sub-dimensions. These sub-dimensions are related to each other; therefore, they can be considered as both three sub-scores and a single total score. The lowest score that can be obtained from the scale is ten, and the highest score is 50 . The lowest score that can be obtained from the Personality Traits Scale is seven, the highest score is 35. The lowest score that can be obtained from the Professional Development Scale is four, and the highest score is 20. So, there are 25 items in the Effective Teacher Characteristics Inventory. All scales in the inventory are arranged as 5-point Likert (Never [1], Rarely [2], Sometimes [3], Often [4], and Always [5]). Reliability value for 
Subject Matter Knowledge is 0.82; 0.74 for Instructional Skills Scale; 0.86 for Personality Traits, and 0.77 for Professional Development. In the literature, these values are accepted as high reliability values (Büyüköztürk, 2013; Field, 2018; Özdamar, 2013). In the data analysis, descriptive statistics and comparison tests were used. According to the Kolmogorov-Smirnov normality test, it was determined that the total scores of subject matter knowledge, instructional skills, personality traits, and professional development scales did not show normal distribution $(\mathrm{p}<.05)$. Therefore, Mann-Whitney U Test and Kruskal Wallis Test were used in the comparison.

The results revealed that public school teachers perceive themselves as more competent than private school teachers in terms of subject matter knowledge and give more importance to professional development than private school teachers; private school teachers perceive themselves as more competent than public school teachers in terms of instructional skills. However, in terms of personality traits, both public and private school teachers perceive themselves as positive. Gender and branch do not make any significant difference with regard to subject matter knowledge, instructional skills, personality traits, and professional development. Similarly, seniority does not make any significant difference in terms of personality traits and professional development. However, it was concluded that teachers with 0-5 years of experience perceive themselves as more competent in terms of instructional skills than those with experience of 21 years or more. This may be due to the fact that newly graduated teachers focus more on instructional knowledge and skills and develop themselves more in this field. This finding is in line with the studies conducted by Tosuntaş, Çubukçu, and Beauchamp (2021) and Tran and Do (2020).

The following are some implications for (1) Decision-Makers/Education Policy Makers, (2) Researchers, (3) Practitioners (Teachers):

Implications for Decision-Makers/Education Policy Makers:

1. Teacher education curriculum can be revised, and curriculum evaluation studies can be conducted to increase the awareness of teacher candidates about effective teacher characteristics.

2. In-service training can be organized to increase the knowledge, skills and competencies of teachers working in both public and private schools on effective teacher characteristics and to support their lifelong learning.

3. Studies can be carried out by the Ministry of National Education, in which teachers can evaluate themselves in terms of effective teacher characteristics, and the results of these studies can be shared with all teachers to increase teachers' awareness on this subject. 
Implications for Researchers:

1. Studies that examine student views can be conducted to determine the characteristics of effective teachers.

2. Research can be conducted on what prospective teachers think about the characteristics that an effective teacher should have and where they perceive themselves regarding these characteristics.

3. A needs analysis study can be conducted to determine the characteristics that teachers feel inadequate about the effective teacher characteristics.

Implications for Practitioners (Teachers):

1. Teachers can contribute to both their personal and professional development by following relevant scientific research and focusing on reflecting the results of these studies on their professional practices to adopt a perspective on lifelong learning and develop effective teacher characteristics.

2. Teachers can carry out evaluation studies (by giving students the opportunity to evaluate their teachers) that they will organize periodically on the basis of the classes they teach. These types of work can help teachers to self-evaluate and provide the necessary transformation about their future practices.

\section{Araştırmacıların Katkı Oranı Beyanı}

$\mathrm{Bu}$ araştırmanın planlanması, yürütülmesi ve yazılı hale getirilmesinde sadece tek bir araştırmacı yer almıştır.

\section{Destek ve Teşekkür Beyanı}

$\mathrm{Bu}$ araştırmada herhangi bir kurum, kuruluş ya da kişiden destek alınmamıştır.

\section{Çatışma Beyanı}

Araştırmacının araştırma ile ilgili diğer kişi ve kurumlarla herhangi bir kişisel ve finansal çıkar çatışması yoktur.

\section{Etik Kurul Beyanı}

Bu araştırma, Çanakkale Onsekiz Mart Üniversitesi, Lisansüstü Eğitim Enstitüsü Etik Kurulunun 11.03.2021 tarih ve 05/34 sayılı kararı ile yürütülmüştür. 